\title{
Non-convex hybrid algorithm for a family of countable quasi-Lipschitz mappings and application
}

\author{
Jinyu Guan ${ }^{1}$, Yanxia Tang ${ }^{1}$, Pengcheng Ma ${ }^{1}$, Yongchun $\mathrm{Xu}^{1 *}$ and Yongfu Su${ }^{2}$
}

\section{"Correspondence:}

hbxuyongchun@163.com

'Department of Mathematics,

Hebei North University,

Zhangjiakou, 075000, China

Full list of author information is

available at the end of the article

\section{空 Springer}

\begin{abstract}
The purpose of this article is to establish a kind of non-convex hybrid iteration algorithms and to prove relevant strong convergence theorems of common fixed points for a uniformly closed asymptotically family of countable quasi-Lipschitz mappings in Hilbert spaces. Meanwhile, the main result is applied to get the common fixed points of finite family of quasi-asymptotically nonexpansive mappings. It is worth pointing out that a non-convex hybrid iteration algorithm is first presented in this article, a new technique is applied in our process of proof. Finally, an example is given which is a uniformly closed asymptotically family of countable quasi-Lipschitz mappings. The results presented in this article are interesting extensions of some current results.
\end{abstract}

MSC: $47 \mathrm{H} 05 ; 47 \mathrm{H} 09 ; 47 \mathrm{H} 10$

Keywords: nonexpansive mapping; hybrid algorithm; Cauchy sequence; closed quasi-nonexpansive

\section{Introduction}

Construction of fixed points of nonexpansive mappings (and asymptotically nonexpansive mappings) is an important subject in the theory of nonexpansive mappings and finds application in a number of applied areas. Recently, a great deal of literature on iteration algorithms for approximating fixed points of nonexpansive mappings has been published since one has a variety of applications in inverse problem, image recovery, and signal processing; see [1-8]. Mann's iteration process [1] is often used to approximate a fixed point of the operators, but it has only weak convergence (see [3] for an example). However, strong convergence is often much more desirable than weak convergence in many problems that arise in infinite dimensional spaces (see [7] and references therein). So, attempts have been made to modify Mann's iteration process so that strong convergence is guaranteed (see [9-24] and references therein).

In 2003, Nakajo and Takahashi [25] proposed a modification of Mann iteration method for a single nonexpansive mapping in a Hilbert space. In 2006, Kim and Xu [26] proposed a modification of Mann iteration method for asymptotically nonexpansive mapping $T$ in a Hilbert space. They also proposed a modification of the Mann iteration method for asymptotically nonexpansive semigroup in a Hilbert space. In 2006, Martinez-Yanes and Xu [27]

(c) 2015 Guan et al. This article is distributed under the terms of the Creative Commons Attribution 4.0 International License (http://creativecommons.org/licenses/by/4.0/), which permits unrestricted use, distribution, and reproduction in any medium, provided you give appropriate credit to the original author(s) and the source, provide a link to the Creative Commons license, and indicate if changes were made. 
proposed a modification of the Ishikawa iteration method for nonexpansive mapping in a Hilbert space. Martinez-Yanes and Xu [27] proposed also a modification of the Halpern iteration method for nonexpansive mapping in a Hilbert space. In 2008, Su and Qin [28] proposed first a monotone hybrid iteration method for nonexpansive mapping in a Hilbert space. In 2015, Dong and $\mathrm{Lu}$ [29] proposed a new iteration method for nonexpansive mapping in a Hilbert space. In 2015, Liu et al. [30] proposed a new iteration method for a finite family of quasi-asymptotically pseudocontractive mappings in a Hilbert spaces.

Throughout this paper, let $H$ be a real Hilbert space with inner product $\langle\cdot, \cdot\rangle$ and norm $\|\cdot\|$. We write $x_{n} \rightarrow x$ to indicate that the sequence $\left\{x_{n}\right\}$ converges strongly to $x$. We write $x_{n} \rightarrow x$ to indicate that the sequence $\left\{x_{n}\right\}$ converges weakly to $x$. Let $C$ be a nonempty, closed, and convex subset of $H$, we denote by $P_{C}(\cdot)$ the metric projection onto $C$. It is well known that $z=P_{C}(x)$ is equivalent to that $z \in C$ and $\langle z-y, x-z\rangle \geq 0$ for every $y \in C$. Recall that $T: C \rightarrow C$ is nonexpansive if $\|T x-T y\| \leq\|x-y\|$ for all $x, y \in C$. A point $x \in C$ is a fixed point of $T$ provided $T x=x$. Denote by $F(T)$ the set of fixed points of $T$, that is, $F(T)=\{x \in C: T x=x\}$. It is well known that $F(T)$ is closed and convex. A mapping $T: C \rightarrow C$ is said to be quasi-Lipschitz, if the following conditions hold:

(1) the fixed point set $F(T)$ is nonempty;

(2) $\|T x-p\| \leq L\|x-p\|$ for all $x \in C, p \in F(T)$,

where $1 \leq L<+\infty$ is a constant. $T$ is said to be quasi-nonexpansive, if $L=1$.

Recall that a mapping $T: C \rightarrow C$ is said to be closed if $x_{n} \rightarrow x$ and $\left\|T x_{n}-x_{n}\right\| \rightarrow 0$ as $n \rightarrow \infty$ implies $T x=x$. A mapping $T: C \rightarrow C$ is said to be weak closed if $x_{n} \rightarrow x$ and $\left\|T x_{n}-x_{n}\right\| \rightarrow 0$ as $n \rightarrow \infty$ implies $T x=x$. It is obvious that a weak closed mapping must be a closed mapping, the inverse is not true.

Let $C$ be a nonempty, closed, and convex subset of a Hilbert space $H$. Let $\left\{T_{n}\right\}$ be sequence of mappings from $C$ into itself with a nonempty common fixed point set $F$. $\left\{T_{n}\right\}$ is said to be uniformly closed if for any convergent sequence $\left\{z_{n}\right\} \subset C$ such that $\left\|T_{n} z_{n}-z_{n}\right\| \rightarrow 0$ as $n \rightarrow \infty$, the limit of $\left\{z_{n}\right\}$ belongs to $F$.

The purpose of this article is to establish a kind of non-convex hybrid iteration algorithms and to prove relevant strong convergence theorems of common fixed points for a uniformly closed asymptotically family of countable quasi-Lipschitz mappings in Hilbert spaces. Meanwhile, the main result was applied to get the common fixed points of finite family of quasi-asymptotically nonexpansive mappings. It is worth pointing out that a nonconvex hybrid iteration algorithm was first presented in this article, a new technique has been applied in our process of proof. Finally, an example has been given which is a uniformly closed asymptotically family of countable quasi-Lipschitz mappings. The results presented in this article are interesting extensions of some current results.

\section{Main results}

The following lemma is well known and is useful for our conclusions.

Lemma 2.1 Let $C$ be a nonempty, closed, and convex subset of real Hilbert space H. Given $x \in H$ and $z \in C$. Then $z=P_{C} x$ if and only if we have the relation

$$
\langle x-z, z-y\rangle \geq 0
$$

for all $y \in C$. 
Definition 2.2 Let $H$ be a Hilbert space, let $C$ be a closed convex subset of $E$, and let $\left\{T_{n}\right\}$ be a family of countable quasi- $L_{n}$-Lipschitz mappings from $C$ into itself, $\left\{T_{n}\right\}$ is said to be asymptotically, if $\lim _{n \rightarrow \infty} L_{n}=1$.

Lemma 2.3 Let $H$ be a Hilbert space, let $C$ be a closed convex subset of $E$, and let $\left\{T_{n}\right\}$ be a uniformly closed asymptotically family of countable quasi- $L_{n}$-Lipschitz mappings from $C$ into itself. Then the common fixed point set $F$ is closed and convex.

Proof Let $p_{n} \in F$ and $p_{n} \rightarrow p$ as $n \rightarrow \infty$, we have

$$
\left\|T_{n} p_{n}-p_{n}\right\|=0 \rightarrow 0, \quad p_{n} \rightarrow p
$$

as $n \rightarrow \infty$. Since $\left\{T_{n}\right\}$ is uniformly closed, we know that $p \in F$, therefore $F$ is closed. Next we show that $F$ is also convex. For any $x, y \in F$, let $z=t x+(1-t) y$ for any $t \in(0,1)$, we have

$$
\begin{aligned}
\left\|T_{n} z-z\right\|^{2}= & \left\langle T_{n} z-z, T_{n} z-z\right\rangle \\
= & \left\|T_{n} z\right\|^{2}-2\left\langle T_{n} z, z\right\rangle+\|z\|^{2} \\
= & \left\|T_{n} z\right\|^{2}-2\left\langle T_{n} z, t x+(1-t) y\right\rangle+\|z\|^{2} \\
= & \left\|T_{n} z\right\|^{2}-2 t\left\langle T_{n} z, x\right\rangle+2(1-t)\left\langle T_{n} z, y\right\rangle+\|z\|^{2} \\
= & t\left\|T_{n} z-x\right\|^{2}+(1-t)\left\|T_{n} z-y\right\|^{2}-t\|x\|^{2}-(1-t)\|y\|^{2}+\|z\|^{2} \\
\leq & t L_{n}^{2}\|z-x\|^{2}+(1-t) L_{n}^{2}\|z-y\|^{2}-t\|x\|^{2}-(1-t)\|y\|^{2}+\|z\|^{2} \\
= & t\|z-x\|^{2}+(1-t)\|z-y\|^{2}-t\|x\|^{2}-(1-t)\|y\|^{2}+\|z\|^{2} \\
& +t\left(L_{n}^{2}-1\right)\|z-x\|^{2}+(1-t)\left(L_{n}^{2}-1\right)\|y-x\|^{2} \\
= & \|z\|^{2}-2\langle z, z\rangle+\|z\|^{2} \\
& +t\left(L_{n}^{2}-1\right)\|z-x\|^{2}+(1-t)\left(L_{n}^{2}-1\right)\|y-x\|^{2} \rightarrow 0
\end{aligned}
$$

as $n \rightarrow \infty$. Since $z \rightarrow z$, and $\left\{T_{n}\right\}$ is uniformly closed, $z \in F$. Therefore $F$ is convex. This completes the proof.

The following conclusion is well known.

Lemma 2.4 Let $C$ be a closed convex subset of a Hilbert space $H$, for any given $x_{0} \in H$, we have

$$
p=P_{C} x_{0} \quad \Leftrightarrow \quad\left\langle p-z, x_{0}-p\right\rangle \geq 0, \quad \forall z \in C
$$

Theorem 2.5 Let $C$ be a closed convex subset of a Hilbert space $H$, and let $\left\{T_{n}\right\}: C \rightarrow C$ be a uniformly closed asymptotically family of countable quasi- $L_{n}$-Lipschitz mappings from $C$ into itself. Assume that $\alpha_{n} \in(a, 1]$ holds for some $a \in(0,1)$. Then $\left\{x_{n}\right\}$ generated by

$$
\left\{\begin{array}{l}
x_{0} \in C=Q_{0} \quad \text { chosen arbitrarily, } \\
y_{n}=\left(1-\alpha_{n}\right) x_{n}+\alpha_{n} T_{n} x_{n}, \quad n \geq 0, \\
C_{n}=\left\{z \in C:\left\|y_{n}-z\right\| \leq\left(1+\left(L_{n}-1\right) \alpha_{n}\right)\left\|x_{n}-z\right\|\right\} \cap A, \quad n \geq 0, \\
Q_{n}=\left\{z \in Q_{n-1}:\left\langle x_{n}-z, x_{0}-x_{n}\right\rangle \geq 0\right\}, \quad n \geq 1, \\
x_{n+1}=P_{\overline{\mathrm{co}} C_{n} \cap Q_{n}} x_{0},
\end{array}\right.
$$


converges strongly to $P_{F} x_{0}$, where $\overline{\mathrm{co}} C_{n}$ denotes the closed convex closure of $C_{n}$ for all $n \geq 1$, $A=\left\{z \in H:\left\|z-P_{F} x_{0}\right\| \leq 1\right\}$.

Proof We split the proof into seven steps.

Step 1. It is obvious that $\overline{\mathrm{co}} C_{n}, Q_{n}$ are closed and convex for all $n \geq 0$. Next, we show that $F \cap A \subset \overline{\operatorname{co}} C_{n}$ for all $n \geq 0$. Indeed, for each $p \in F \cap A$, we have

$$
\begin{aligned}
\left\|y_{n}-p\right\| & =\left\|\left(1-\alpha_{n}\right) x_{n}+\alpha_{n} T_{n} x_{n}-p\right\| \\
& =\left\|\alpha_{n}\left(x_{n}-p\right)+\left(1-\alpha_{n}\right)\left(T_{n} x_{n}-p\right)\right\| \\
& \leq\left(1-\alpha_{n}\right)\left\|x_{n}-p\right\|+\alpha_{n} L_{n}\left\|x_{n}-p\right\| \\
& =\left(1+\left(L_{n}-1\right) \alpha_{n}\right)\left\|x_{n}-z\right\|
\end{aligned}
$$

and $p \in A$, so $p \in C_{n}$ which implies that $F \cap A \subset C_{n}$ for all $n \geq 0$. Therefore, $F \cap A \subset \overline{\text { co }} C_{n}$ for all $n \geq 0$.

Step 2. We show that $F \cap A \subset \overline{\operatorname{co}} C_{n} \cap Q_{n}$ for all $n \geq 0$. It suffices to show that $F \cap A \subset Q_{n}$, for all $n \geq 0$. We prove this by mathematical induction. For $n=0$, we have $F \cap A \subset C=Q_{0}$. Assume that $F \cap A \subset Q_{n}$. Since $x_{n+1}$ is the projection of $x_{0}$ onto $\overline{c o} C_{n} \cap Q_{n}$, from Lemma 2.1, we have

$$
\left\langle x_{n+1}-z, x_{n+1}-x_{0}\right\rangle \leq 0, \quad \forall z \in \overline{\mathrm{co}} C_{n} \cap Q_{n}
$$

as $F \cap A \subset \overline{c o} C_{n} \cap Q_{n}$, the last inequality holds, in particular, for all $z \in F \cap A$. This together with the definition of $Q_{n+1}$ implies that $F \cap A \subset Q_{n+1}$. Hence the $F \cap A \subset \overline{c o} C_{n} \cap Q_{n}$ holds for all $n \geq 0$.

Step 3 . We prove $\left\{x_{n}\right\}$ is bounded. Since $F$ is a nonempty, closed, and convex subset of $C$, there exists a unique element $z_{0} \in F$ such that $z_{0}=P_{F} x_{0}$. From $x_{n+1}=P_{\overline{\mathrm{co}}} C_{n} \cap Q_{n} x_{0}$, we have

$$
\left\|x_{n+1}-x_{0}\right\| \leq\left\|z-x_{0}\right\|
$$

for every $z \in \overline{\mathrm{co}} C_{n} \cap Q_{n}$. As $z_{0} \in F \cap A \subset \overline{\mathrm{co}} C_{n} \cap Q_{n}$, we get

$$
\left\|x_{n+1}-x_{0}\right\| \leq\left\|z_{0}-x_{0}\right\|
$$

for each $n \geq 0$. This implies that $\left\{x_{n}\right\}$ is bounded.

Step 4 . We show that $\left\{x_{n}\right\}$ converges strongly to a point of $C$ (we show that $\left\{x_{n}\right\}$ is a Cauchy sequence). As $x_{n+1}=P_{\overline{\mathrm{co}} C_{n} \cap Q_{n}} x_{0} \subset Q_{n}$ and $x_{n}=P_{Q_{n}} x_{0}$ (Lemma 2.4), we have

$$
\left\|x_{n+1}-x_{0}\right\| \geq\left\|x_{n}-x_{0}\right\|
$$

for every $n \geq 0$, which together with the boundedness of $\left\|x_{n}-x_{0}\right\|$ implies that there exists the limit of $\left\|x_{n}-x_{0}\right\|$. On the other hand, from $x_{n+m} \in Q_{n}$, we have $\left\langle x_{n}-x_{n+m}, x_{n}-x_{0}\right\rangle \leq 0$ and hence

$$
\begin{aligned}
\left\|x_{n+m}-x_{n}\right\|^{2} & =\left\|\left(x_{n+m}-x_{0}\right)-\left(x_{n}-x_{0}\right)\right\|^{2} \\
& \leq\left\|x_{n+m}-x_{0}\right\|^{2}-\left\|x_{n}-x_{0}\right\|^{2}-2\left\langle x_{n+m}-x_{n}, x_{n}-x_{0}\right\rangle \\
& \leq\left\|x_{n+m}-x_{0}\right\|^{2}-\left\|x_{n}-x_{0}\right\|^{2} \rightarrow 0, \quad n \rightarrow \infty
\end{aligned}
$$


for any $m \geq 1$. Therefore $\left\{x_{n}\right\}$ is a Cauchy sequence in $C$, then there exists a point $q \in C$ such that $\lim _{n \rightarrow \infty} x_{n}=q$.

Step 5 . We show that $y_{n} \rightarrow q$, as $n \rightarrow \infty$. Let

$$
D_{n}=\left\{z \in C:\left\|y_{n}-z\right\|^{2} \leq\left\|x_{n}-z\right\|^{2}+4\left(L_{n}-1\right)\left(L_{n}+1\right)\right\} .
$$

From the definition of $D_{n}$, we have

$$
\begin{aligned}
D_{n} & =\left\{z \in C:\left\langle y_{n}-z, y_{n}-z\right\rangle \leq\left\langle x_{n}-z, x_{n}-z\right\rangle+\left(L_{n}-1\right)\left(L_{n}+1\right) 2\right\} \\
& =\left\{z \in C:\left\|y_{n}\right\|^{2}-2\left\langle y_{n}, z\right\rangle+\|z\|^{2} \leq\left\|x_{n}\right\|^{2}-2\left\langle x_{n}, z\right\rangle+\|z\|^{2}+4\left(L_{n}-1\right)\left(L_{n}+1\right)\right\} \\
& =\left\{z \in C: 2\left\langle x_{n}-y_{n}, z\right\rangle \leq\left\|x_{n}\right\|^{2}-\left\|y_{n}\right\|^{2}+4\left(L_{n}-1\right)\left(L_{n}+1\right)\right\} .
\end{aligned}
$$

This implies that $D_{n}$ is closed and convex, for all $n \geq 0$. Next, we show that

$$
C_{n} \subset D_{n}, \quad n \geq 0 .
$$

In fact, for any $z \in C_{n}$, we have

$$
\begin{aligned}
\left\|y_{n}-z\right\|^{2} & \leq\left(1+\left(L_{n}-1\right) \alpha_{n}\right)^{2}\left\|x_{n}-z\right\|^{2} \\
& =\left\|x_{n}-z\right\|^{2}+\left[2\left(L_{n}-1\right) \alpha_{n}+\left(L_{n}-1\right)^{2} \alpha_{n}^{2}\right]\left\|x_{n}-z\right\|^{2} \\
& \leq\left\|x_{n}-z\right\|^{2}+\left[2\left(L_{n}-1\right)+\left(L_{n}-1\right)^{2}\right]\left\|x_{n}-z\right\|^{2} \\
& =\left\|x_{n}-z\right\|^{2}+\left(L_{n}-1\right)\left(L_{n}+1\right)\left\|x_{n}-z\right\|^{2} .
\end{aligned}
$$

From

$$
C_{n}=\left\{z \in C:\left\|y_{n}-z\right\| \leq\left(1+\left(L_{n}-1\right) \alpha_{n}\right)\left\|x_{n}-z\right\|\right\} \cap A, \quad n \geq 0,
$$

we have $C_{n} \subset A, n \geq 0$. Since $A$ is convex, we also have $\overline{c o} C_{n} \subset A, n \geq 0$. Consider $x_{n} \in$ $\overline{\mathrm{co}} C_{n-1}$, we know that

$$
\begin{aligned}
\left\|y_{n}-z\right\|^{2} & \leq\left\|x_{n}-z\right\|^{2}+\left(L_{n}-1\right)\left(L_{n}+1\right)\left\|x_{n}-z\right\|^{2} \\
& \leq\left\|x_{n}-z\right\|^{2}+4\left(L_{n}-1\right)\left(L_{n}+1\right) .
\end{aligned}
$$

This implies that $z \in D_{n}$ and hence $C_{n} \subset D_{n}, n \geq 0$. Since $D_{n}$ is convex, we have $\overline{\operatorname{co}}\left(C_{n}\right) \subset$ $D_{n}, n \geq 0$. Therefore

$$
\left\|y_{n}-x_{n+1}\right\|^{2} \leq\left\|x_{n}-x_{n+1}\right\|^{2}+4\left(L_{n}-1\right)\left(L_{n}+1\right) \rightarrow 0
$$

as $n \rightarrow \infty$. That is, $y_{n} \rightarrow q$ as $n \rightarrow \infty$.

Step 6 . We show that $q \in F$. From the definition of $y_{n}$, we have

$$
\alpha_{n}\left\|T_{n} x_{n}-x_{n}\right\|=\left\|y_{n}-x_{n}\right\| \rightarrow 0
$$


as $n \rightarrow \infty$. Since $\alpha_{n} \in(a, 1] \subset[0,1]$, from the above limit we have

$$
\lim _{n \rightarrow \infty}\left\|T_{n} x_{n}-x_{n}\right\|=0
$$

Since $\left\{T_{n}\right\}$ is uniformly closed and $x_{n} \rightarrow q$, we have $q \in F$.

Step 7. We claim that $q=z_{0}=P_{F} x_{0}$, if not, we have that $\left\|x_{0}-p\right\|>\left\|x_{0}-z_{0}\right\|$. There must exist a positive integer $N$, if $n>N$ then $\left\|x_{0}-x_{n}\right\|>\left\|x_{0}-z_{0}\right\|$, which leads to

$$
\left\|z_{0}-x_{0}\right\|^{2}=\left\|z_{0}-x_{n}+x_{n}-x_{0}\right\|^{2}=\left\|z_{0}-x_{n}\right\|^{2}+\left\|x_{n}-x_{0}\right\|^{2}+2\left\langle z_{0}-x_{n}, x_{n}-x_{0}\right\rangle .
$$

It follows that $\left\langle z_{0}-x_{n}, x_{n}-x_{0}\right\rangle<0$ which implies that $z_{0} \bar{\epsilon} Q_{n}$, so that $z_{0} \bar{\epsilon} F$, this is a contradiction. This completes the proof.

Next, we give an example of $C_{n}$ not involving a convex subset.

Example 2.6 Let $H=R^{2}, T_{n}: R^{2} \rightarrow R^{2}$ be a sequence of mappings defined by

$$
T_{n}:\left(t_{1}, t_{2}\right) \mapsto\left(t_{1}, \frac{1}{8} t_{2}\right), \quad \forall\left(t_{1}, t_{2}\right) \in R^{2}, \forall n \geq 0 .
$$

It is obvious that $\left\{T_{n}\right\}$ is a uniformly closed asymptotically family of countable quasi- $L_{n}$ Lipschitz mappings with the common fixed point set $F=\left\{\left(t_{1}, 0\right): t_{1} \in(-\infty,+\infty)\right\}$. Take $x_{0}=(4,0), \alpha_{0}=\frac{6}{7}$, we have

$$
y_{0}=\frac{1}{7} x_{0}+\frac{6}{7} T_{0} x_{0}=\left(4 \times \frac{1}{7}+\frac{4}{8} \times \frac{6}{7}, 0\right)=(1,0) .
$$

Take $1+\left(L_{0}-1\right) \alpha_{0}=\sqrt{\frac{5}{2}}$, we have

$$
C_{0}=\left\{z \in R^{2}:\left\|y_{0}-z\right\| \leq \sqrt{\frac{5}{2}}\left\|x_{0}-z\right\|\right\}
$$

It is easy to show that $z_{1}=(1,3), z_{2}=(-1,3) \in C_{0}$. But

$$
z^{\prime}=\frac{1}{2} z_{1}+\frac{1}{2} z_{2}=(0,3) \bar{\in} C_{0},
$$

since $\left\|y_{0}-z^{\prime}\right\|=2,\left\|x_{0}-z^{\prime}\right\|=1$. Therefore $C_{0}$ is not convex.

Corollary 2.7 Let $C$ be a closed convex subset of a Hilbert space $H$, and let $T: C \rightarrow C$ be a closed quasi-nonexpansive mapping from $C$ into itself. Assume that $\alpha_{n} \in(a, 1]$ holds for some $a \in(0,1)$. Then $\left\{x_{n}\right\}$ generated by

$$
\left\{\begin{array}{l}
x_{0} \in C=Q_{0} \quad \text { chosen arbitrarily, } \\
y_{n}=\left(1-\alpha_{n}\right) x_{n}+\alpha_{n} T x_{n}, \quad n \geq 0, \\
C_{n}=\left\{z \in C:\left\|y_{n}-z\right\| \leq\left\|x_{n}-z\right\|\right\} \cap A, \quad n \geq 0, \\
Q_{n}=\left\{z \in Q_{n-1}:\left\langle x_{n}-z, x_{0}-x_{n}\right\rangle \geq 0\right\}, \quad n \geq 1, \\
x_{n+1}=P_{C_{n} \cap Q_{n}} x_{0},
\end{array}\right.
$$

converges strongly to $P_{F(T)} x_{0}$, where $A=\left\{z \in H:\left\|z-P_{F} x_{0}\right\| \leq 1\right\}$. 
Proof Take $T_{n} \equiv T, L_{n} \equiv 1$ in Theorem 2.5, in this case, $C_{n}$ is closed and convex, for all $n \geq 0$, by using Theorem 2.5, we obtain Corollary 2.7.

Since a nonexpansive mapping must be a closed quasi-nonexpansive mapping, from Corollary 2.7, we obtain the following result.

Corollary 2.8 Let $C$ be a closed convex subset of a Hilbert space $H$, and let $T: C \rightarrow C$ be a nonexpansive mapping from $C$ into itself. Assume that $\alpha_{n} \in(a, 1]$ holds for some $a \in(0,1)$. Then $\left\{x_{n}\right\}$ generated by

$$
\left\{\begin{array}{l}
x_{0} \in C=Q_{0} \quad \text { chosen arbitrarily, } \\
y_{n}=\left(1-\alpha_{n}\right) x_{n}+\alpha_{n} T x_{n}, \quad n \geq 0, \\
C_{n}=\left\{z \in C:\left\|y_{n}-z\right\| \leq\left\|x_{n}-z\right\|\right\} \cap A, \quad n \geq 0, \\
Q_{n}=\left\{z \in Q_{n-1}:\left\langle x_{n}-z, x_{0}-x_{n}\right\rangle \geq 0\right\}, \quad n \geq 1, \\
x_{n+1}=P_{C_{n} \cap Q_{n}} x_{0},
\end{array}\right.
$$

converges strongly to $P_{F(T)} x_{0}$, where $A=\left\{z \in H:\left\|z-P_{F} x_{0}\right\| \leq 1\right\}$.

\section{Application to family of quasi-asymptotically nonexpansive mappings}

In this section, we will apply the above result to study the following finite family of asymptotically quasi-nonexpansive mappings $\left\{T_{n}\right\}_{n=0}^{N-1}$. Let

$$
\left\|T_{i}^{j} x-p\right\| \leq k_{i, j}\|x-p\|, \quad \forall x \in C, p \in F
$$

where $F$ denotes the common fixed point set of $\left\{T_{n}\right\}_{n=0}^{N-1}, \lim _{j \rightarrow \infty} k_{i, j}=1$ for all $0 \leq i \leq$ $N-1$. The finite family of asymptotically quasi-nonexpansive mappings $\left\{T_{n}\right\}_{n=0}^{N-1}$ is said to be uniformly $L$-Lipschitz, if

$$
\left\|T_{i}^{j} x-T_{i}^{j} y\right\| \leq L\|x-y\|, \quad \forall x, y \in C
$$

for all $i=0,1,2, \ldots, N-1, j \geq 1$, where $L \geq 1$.

Theorem 3.1 Let C be a closed convex subset of a Hilbert space $H$, and let $\left\{T_{n}\right\}_{n=0}^{N-1}: C \rightarrow C$ be a uniformly L-Lipschitz finite family of asymptotically quasi-nonexpansive mappings with nonempty common fixed point set $F$. Assume that $\alpha_{n} \in(a, 1]$ holds for some $a \in(0,1)$. Then $\left\{x_{n}\right\}$ generated by

$$
\left\{\begin{array}{l}
x_{0} \in C=Q_{0} \quad \text { chosen arbitrarily, } \\
y_{n}=\left(1-\alpha_{n}\right) x_{n}+\alpha_{n} T_{i(n)}^{j(n)} x_{n}, \quad n \geq 0, \\
C_{n}=\left\{z \in C:\left\|y_{n}-z\right\| \leq\left(1+\left(k_{i(n), j(n)}-1\right) \alpha_{n}\right)\left\|x_{n}-z\right\|\right\} \cap A, \quad n \geq 0, \\
Q_{n}=\left\{z \in Q_{n-1}:\left\langle x_{n}-z, x_{0}-x_{n}\right\rangle \geq 0\right\}, \quad n \geq 1, \\
x_{n+1}=P_{\overline{\mathrm{co}}} C_{n} \cap Q_{n} x_{0},
\end{array}\right.
$$

converges strongly to $P_{F} x_{0}$, where $\overline{c o} C_{n}$ denotes the closed convex closure of $C_{n}$ for all $n \geq 1$, $n=(j(n)-1) N+i(n)$ for all $n \geq 0, A=\left\{z \in H:\left\|z-P_{F} x_{0}\right\| \leq 1\right\}$. 
Proof It is sufficient to prove the following two conclusions.

Conclusion $1\left\{T_{i(n)}^{j(n)}\right\}_{n=0}^{\infty}$ is a uniformly closed asymptotically family of countable quasi- $L_{n}$ Lipschitz mappings from $C$ into itself.

Conclusion $2 F=\bigcap_{n=0}^{N} F\left(T_{n}\right)=\bigcap_{n=0}^{\infty} F\left(T_{i(n)}^{j(n)}\right)$, where $F(T)$ denotes the fixed point set of the mapping $T$.

Proof of Conclusion 1 Let

$$
\left\|T_{i(n)}^{j(n)} x_{n}-x_{n}\right\| \rightarrow 0, \quad x_{n} \rightarrow p
$$

as $n \rightarrow \infty$. Observe that

$$
\begin{aligned}
\left\|T_{i(n)} x_{n}-x_{n}\right\| \leq & \left\|T_{i(n)}^{j(n)} x_{n}-x_{n}\right\|+\left\|T_{i(n)}^{j(n)} x_{n}-T_{i(n)} x_{n}\right\| \\
\leq & \left\|T_{i(n)}^{j(n)} x_{n}-x_{n}\right\|+L\left\|T_{i(n)}^{j(n)-1} x_{n}-x_{n}\right\| \\
\leq & \left\|T_{i(n)}^{j(n)} x_{n}-x_{n}\right\|+L\left\|T_{i(n)}^{j(n-N)} x_{n}-T_{i(n)}^{j(n-N)} x_{n-N}\right\| \\
& \quad+L\left\|T_{i(n-N)}^{j(n-N)} x_{n-N}-x_{n-N}\right\|+L\left\|x_{n-N}-x_{n}\right\| \\
\leq & \left\|T_{i(n)}^{j(n)} x_{n}-x_{n}\right\|+\left(L+L^{2}\right)\left\|x_{n-N}-x_{n}\right\| \\
& +L\left\|T_{i(n-N)}^{j(n-N)} x_{n-N}-x_{n-N}\right\|
\end{aligned}
$$

from which it turns out that $\left\|T_{i(n)} x_{n}-x_{n}\right\| \rightarrow 0$ as $n \rightarrow \infty$. This implies there exists subsequence $\left\{n_{k}\right\} \subset\left\{x_{n}\right\}$ such that

$$
\left\|T_{i} x_{n_{k}}-x_{n_{k}}\right\| \rightarrow 0, \quad i=0,1,2, \ldots, N-1
$$

as $k \rightarrow \infty$. That is, $p \in F=\bigcap_{n=0}^{N-1} F\left(T_{n}\right)$. Therefore, $p \in \bigcap_{n=0}^{\infty} F\left(T_{i(n)}^{j(n)}\right)$, hence $\left\{T_{i(n)}^{j(n)}\right\}$ is uniformly closed. On the other hand, we have

$$
\left\|T_{i(n)}^{j(n)} x-p\right\| \leq k_{i(n), j(n)}\|x-p\|, \quad \forall x \in C, p \in \bigcap_{n=0}^{\infty} F\left(T_{i(n)}^{j(n)}\right)
$$

and $\lim _{n \rightarrow \infty} k_{i(n), j(n)}=1$. So, $\left\{T_{i(n)}^{j(n)}\right\}$ is a uniformly closed asymptotically family of countable quasi- $L_{n}$-Lipschitz mappings from $C$ into itself with $L_{n}=k_{i(n), j(n)}$.

Proof of Conclusion 2 It is obvious that

$$
\bigcap_{n=0}^{N-1} F\left(T_{n}\right) \subset \bigcap_{n=0}^{\infty} F\left(T_{i(n)}^{j(n)}\right) .
$$

On the other hand, for any $p \in \bigcap_{n=0}^{\infty} F\left(T_{i(n)}^{j(n)}\right)$, let $n=0,1,2, \ldots, N-1$, we obtain

$$
p \in F\left(T_{0}\right), \quad p \in F\left(T_{1}\right), \quad p \in F\left(T_{2}\right), \quad \ldots, \quad p \in F\left(T_{n-1}\right),
$$


which implies that

$$
\bigcap_{n=0}^{N-1} F\left(T_{n}\right) \supset \bigcap_{n=0}^{\infty} F\left(T_{i(n)}^{j(n)}\right) .
$$

Hence

$$
\bigcap_{n=0}^{N-1} F\left(T_{n}\right)=\bigcap_{n=0}^{\infty} F\left(T_{i(n)}^{j(n)}\right) .
$$

By using Theorem 2.5, the iterative sequence $\left\{x_{n}\right\}$ converges strongly to $P_{\cap_{n=0}^{\infty} F\left(T_{i(n)}^{j(n)}\right)} x_{0}=$ $P_{F} x_{0}$. This completes the proof of Theorem 3.1.

Corollary 3.2 Let $C$ be a closed convex subset of a Hilbert space $H$, and let $T: C \rightarrow C$ be a L-Lipschitz asymptotically quasi-nonexpansive mappings with nonempty fixed point set $F$. Assume that $\alpha_{n} \in(a, 1]$ holds for some $a \in(0,1)$. Then $\left\{x_{n}\right\}$ generated by

$$
\left\{\begin{array}{l}
x_{0} \in C=Q_{0} \quad \text { chosen arbitrarily, } \\
y_{n}=\left(1-\alpha_{n}\right) x_{n}+\alpha_{n} T^{n} x_{n}, \quad n \geq 0, \\
C_{n}=\left\{z \in C:\left\|y_{n}-z\right\| \leq\left(1+\left(k_{n}-1\right) \alpha_{n}\right)\left\|x_{n}-z\right\|\right\} \cap A, \quad n \geq 0, \\
Q_{n}=\left\{z \in Q_{n-1}:\left\langle x_{n}-z, x_{0}-x_{n}\right\rangle \geq 0\right\}, \quad n \geq 1, \\
x_{n+1}=P_{\overline{\mathrm{co}} C_{n} \cap Q_{n}} x_{0},
\end{array}\right.
$$

converges strongly to $P_{F(T)} x_{0}$, where $\overline{c o} C_{n}$ denotes the closed convex closure of $C_{n}$ for all $n \geq 1, A=\left\{z \in H:\left\|z-P_{F} x_{0}\right\| \leq 1\right\}$.

Proof Take $T_{n} \equiv T$ in Theorem 3.1, we obtain Corollary 3.2.

Since a nonexpansive mapping must be a Lipschitz asymptotically quasi-nonexpansive mapping, from Corollary 3.2, we can obtain Corollary 2.8.

\section{Example}

Conclusion 4.1 Let $H$ be a Hilbert space, $\left\{x_{n}\right\}_{n=1}^{\infty} \subset H$ be a sequence such that it converges weakly to a non-zero element $x_{0}$ and $\left\|x_{i}-x_{j}\right\| \geq 1$ for any $i \neq j$. Define a sequence of mappings $T_{n}: H \rightarrow H$ as follows:

$$
T_{n}(x)= \begin{cases}L_{n} x_{n} & \text { if } x=x_{n}(\exists n \geq 1), \\ -x & \text { if } x \neq x_{n}(\forall n \geq 1)\end{cases}
$$

where $\left\{L_{n}\right\}_{n=1}^{\infty}$ is a sequence of number such that $L_{n}>1, \lim _{n \rightarrow \infty} L_{n}=1$. Then $\left\{T_{n}\right\}$ is a uniformly closed asymptotically family of countable quasi- $L_{n}$-Lipschitz mappings with the common fixed point set $F=\{0\}$.

Proof It is obvious that $\left\{T_{n}\right\}$ has a unique common fixed point 0 . Next, we prove that $\left\{T_{n}\right\}$ is uniformly closed. In fact, for any strong convergent sequence $\left\{z_{n}\right\} \subset E$ such that $z_{n} \rightarrow z_{0}$ and $\left\|z_{n}-T_{n} z_{n}\right\| \rightarrow 0$ as $n \rightarrow \infty$, there exists sufficiently large natural number $N$ such that 
$z_{n} \neq x_{m}$, for any $n, m>N$. Then $T_{n} z_{n}=-z_{n}$ for $n>N$, it follows from $\left\|z_{n}-T_{n} z_{n}\right\| \rightarrow 0$ that $2 z_{n} \rightarrow 0$ and hence $z_{0} \in F$. Finally, from the definition of $\left\{T_{n}\right\}$, we have

$$
\left\|T_{n} x-0\right\|=\left\|T_{n} x\right\| \leq\left\|L_{n} x\right\|=L_{n}\|x-0\|, \quad \forall x \in H,
$$

so that $\left\{T_{n}\right\}$ is a uniformly closed asymptotically family of countable quasi- $L_{n}$-Lipschitz mappings.

Remark In the result of Liu et al. [30], the boundedness of $C$ was assumed and the hybrid iterative process was complex. In our hybrid iterative process, $C_{n}$ was constructed as a non-convex set can makes it more simple, meanwhile, the boundedness of $C$ can be removed. Of course, a new technique has been applied in our process of proof.

\section{Competing interests}

The authors declare that they have no competing interests.

\section{Authors' contributions}

All authors contributed equally and significantly in writing this article. All authors read and approved the final manuscript.

\section{Author details}

'Department of Mathematics, Hebei North University, Zhangjiakou, 075000, China. ${ }^{2}$ Department of Mathematics, Tianjin Polytechnic University, Tianjin, 300387, China.

\section{Acknowledgements}

This project is supported by major project of Hebei North University under grant (No. ZD201304).

Received: 28 July 2015 Accepted: 5 November 2015 Published online: 21 November 2015

\section{References}

1. Mann, WR: Mean value methods in iteration. Proc. Am. Math. Soc. 4, 506-510 (1953)

2. Halpern, B: Fixed points of nonexpanding maps. Bull. Am. Math. Soc. 73, 957-961 (1967)

3. Genel, A, Lindenstrass, J: An example concerning fixed points. Isr. J. Math. 22, 81-86 (1975)

4. Youla, D: Mathematical theory of image restoration by the method of convex projection. In: Stark, H (ed.) Image Recovery: Theory and Applications, pp. 29-77. Academic Press, Orlando (1987)

5. Moudafi, A: Viscosity approximation methods for fixed-points problems. J. Math. Anal. Appl. 241, 46-55 (2000)

6. Xu, HK: Viscosity approximation methods for nonexpansive mappings. J. Math. Anal. Appl. 298, 279-291 (2004)

7. Bauschke, HH, Combettes, PL: A weak-to-strong convergence principle for Fejér-monotone methods in Hilbert spaces. Math. Oper. Res. 26(2), 248-264 (2001)

8. Podilchuk, $\mathrm{Cl}$, Mammone, RJ: Image recovery by convex projections using a least-squares constraint. J. Opt. Soc. Am. 7(3), 517-521 (1990)

9. Matsushita, S-Y, Takahashi, W: A strong convergence theorem for relatively nonexpansive mappings in a Banach space. J. Approx. Theory 134, 257-266 (2005)

10. Alber, Yl: Metric and generalized projection operators in Banach spaces: properties and applications. In: Kartsatos, AG (ed.) Theory and Applications of Nonlinear Operators of Accretive and Monotone Type, pp. 15-50. Dekker, New York (1996)

11. Alber, YI, Reich, S: An iterative method for solving a class of nonlinear operator equations in Banach spaces. Panam. Math. J. 4, 39-54 (1994)

12. Kamimura, S, Takahashi, W: Strong convergence of a proximal-type algorithm in a Banach space. SIAM J. Optim. 13, 938-945 (2002)

13. Cioranescu, I: Geometry of Banach Spaces, Duality Mappings and Nonlinear Problems. Kluwer Academic, Dordrecht (1990)

14. Takahashi, W: Nonlinear Functional Analysis. Yokohama Publishers, Yokohama (2000)

15. Butnariu, D, Reich, S, Zaslavski, AJ: Asymptotic behavior of relatively nonexpansive operators in Banach spaces. J. Appl. Anal. 7, 151-174 (2001)

16. Butnariu, D, Reich, S, Zaslavski, AJ: Weak convergence of orbits of nonlinear operators in reflexive Banach spaces. Numer. Funct. Anal. Optim. 24, 489-508 (2003)

17. Censor, Y, Reich, S: Iterations of paracontractions and firmly nonexpansive operators with applications to feasibility and optimization. Optimization 37, 323-339 (1996)

18. Rockafellar, RT: On the maximality of sums of nonlinear monotone operators. Trans. Am. Math. Soc. 149, 75-88 (1970)

19. Takahashi, W: Convex Analysis and Approximation Fixed Points. Yokohama Publishers, Yokohama (2000) (in Japanese)

20. Kohsaka, F, Takahashi, W: Strong convergence of an iterative sequence for maximal monotone operators in a Banach space. Abstr. Appl. Anal. 2004, 239-249 (2004)

21. Ohsawa, S, Takahashi, W: Strong convergence theorems for resolvents of maximal monotone operators in Banach spaces. Arch. Math. 81, 439-445 (2003) 
22. Reich, S: Constructive techniques for accretive and monotone operators. In: Applied Nonlinear Analysis (Proceedings of the Third International Conference, University of Texas, Arlington, TX, 1978), pp. 335-345. Academic Press, New York (1979)

23. Reich, S: A weak convergence theorem for the alternating method with Bregman distance. In: Kartsatos, AG (ed.) Theory and Applications of Nonlinear Operators of Accretive and Monotone Type, pp. 313-318. Dekker, New York (1996)

24. Solodov, MV, Svaiter, BF: Forcing strong convergence of proximal point iterations in Hilbert space. Math. Program. 87, 189-202 (2000)

25. Nakajo, K, Takahashi, W: Strong convergence theorems for nonexpansive mappings and nonexpansive semigroups. J. Math. Anal. Appl. 279, 372-379 (2003)

26. Kim, T-H, Xu, H-K: Strong convergence of modified Mann iterations for asymptotically mappings and semigroups. Nonlinear Anal. 64, 1140-1152 (2006)

27. Martinez-Yanes, C, Xu, H-K: Strong convergence of the CQ method for fixed point iteration processes. Nonlinear Anal. 64, 2400-2411 (2006)

28. Su, Y, Qin, X: Monotone CQ iteration processes for nonexpansive semigroups and maximal monotone operators. Nonlinear Anal. 68, 3657-3664 (2008)

29. Dong, Q, Lu, Y: A new hybrid algorithm for a nonexpansive mapping. Fixed Point Theory Appl. 2015,37 (2015)

30. Liu, Y, Zheng, L, Wang, P, Zhou, H: Three kinds of new hybrid projection methods for a finite family of quasi-asymptotically pseudocontractive mappings in Hilbert spaces. Fixed Point Theory Appl. 2015, 118 (2015)

\section{Submit your manuscript to a SpringerOpen ${ }^{\circ}$ journal and benefit from:}

- Convenient online submission

Rigorous peer review

- Immediate publication on acceptance

Open access: articles freely available online

- High visibility within the field

- Retaining the copyright to your article 